\title{
Management of Bilateral Uterine Horn Prolapse in a Queen Cat
}

\author{
A. Sabarinathan*, N. Arunmozhi, U. S. Kalyaan, S. Rangasamy, \\ T. Sathiamoorthy and K. Kulasekar
}

Department of Animal Reproduction, Gynaecology and Obstetrics, Madras Veterinary College, Chennai- 600 007, Tamil Nadu, India

*Corresponding author

\section{A B S T R A C T}

\begin{tabular}{l} 
Ke y w o r d s \\
$\begin{array}{l}\text { Bilateral uterine } \\
\text { horn prolapse, } \\
\text { Queen cat - manual } \\
\text { reduction }\end{array}$ \\
\hline Article Info \\
$\begin{array}{l}\text { Accepted: } \\
\text { 23 April } 2020 \\
\text { Available Online: } \\
\text { 10 May 2020 }\end{array}$ \\
\hline
\end{tabular}

A two year old non-descript queen cat weighing $3 \mathrm{~kg}$ was brought to Madras Veterinary College Teaching Hospital with the history of a mass protruding out from the vulva from past 8 hours. A rare case of bilateral uterine horn prolapse in a queen cat and its successful management is reported.

\section{Introduction}

Uterine prolapse, the common post parturient complication in domestic species of animals and it is a rare obstetrical emergency in feline species (Jutkowitz, 2005; Deroy et al., 2015).

Uterine prolapse usually occurs during prolonged labour or abortion or within 48 hours of normal parturition (Roberts and Straw Rodney, 1988) and predisposing factors include severe tenesmus, over relaxation of the pelvic musculature, uterine atony, incomplete placental separation and flaccid mesovaria (Jutkowitz, 2005) which involves one or both horns (Wallace et al., 1970). The present report describes the successful management of postpartum bilateral uterine horn prolapse in a queen cat.

\section{Case History and Observations}

A two year old non-descript queen cat weighing $3 \mathrm{~kg}$ was brought to Madras Veterinary College Teaching Hospital with the history of a mass protruding out from the 
vulva from past 8 hours. Further enquiry revealed that she had kittened two live kittens previous day without assistance and the cat is straining since last night. On general examination the cat appeared dehydrated and was straining continuously.

The mucous membrane was pink, dry with a body temperature of $102^{\circ} \mathrm{F}$ and visual inspection of the prolapsed mass revealed dry, oedematous uterine horns without any laceration. On abdominal palpation no abnormalities revealed. Based on the clinical observations the case was diagnosed as bilateral uterine horn prolapse.

\section{Treatment and Discussion}

Various methods have been described for the treatment of uterine prolapse in cat including amputation of the everted uterus, manual reduction and repositioning by abdominal palpation with fluid infusion and manual reduction of the prolapsed mass through a laparotomy incision, followed by ovariohysterectomy (Johnston et al., 2001) (Fig. 1 and 2).

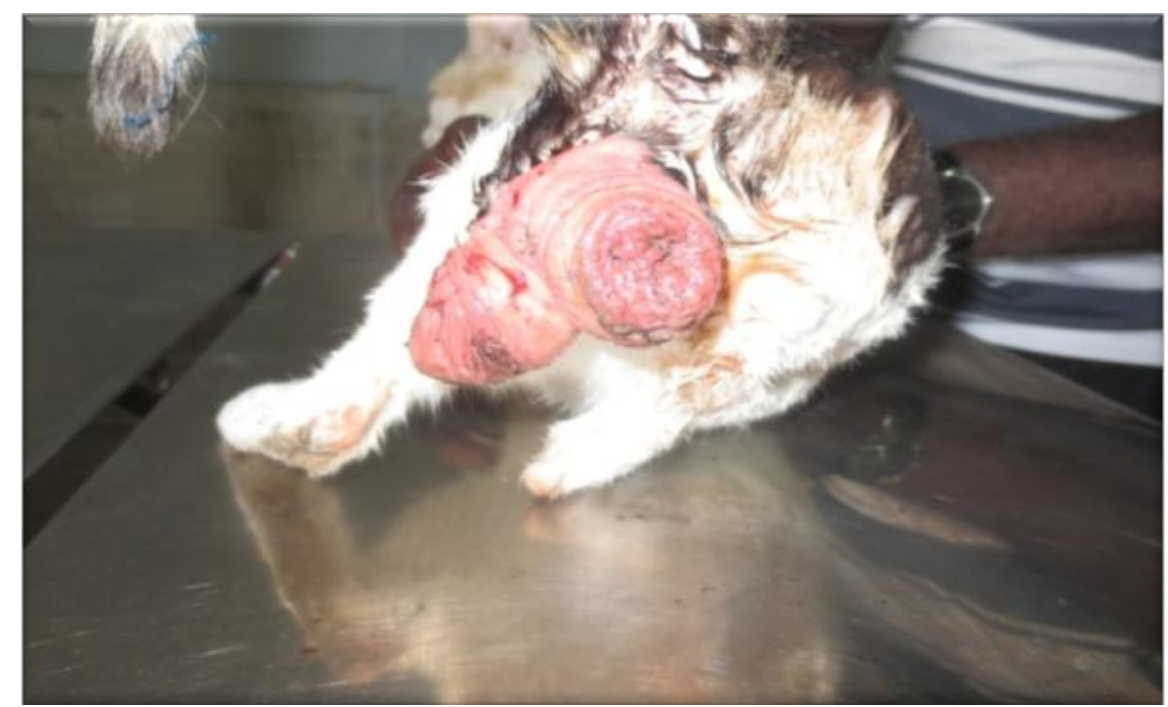

Fig.1 Bilateral uterine horns prolapse

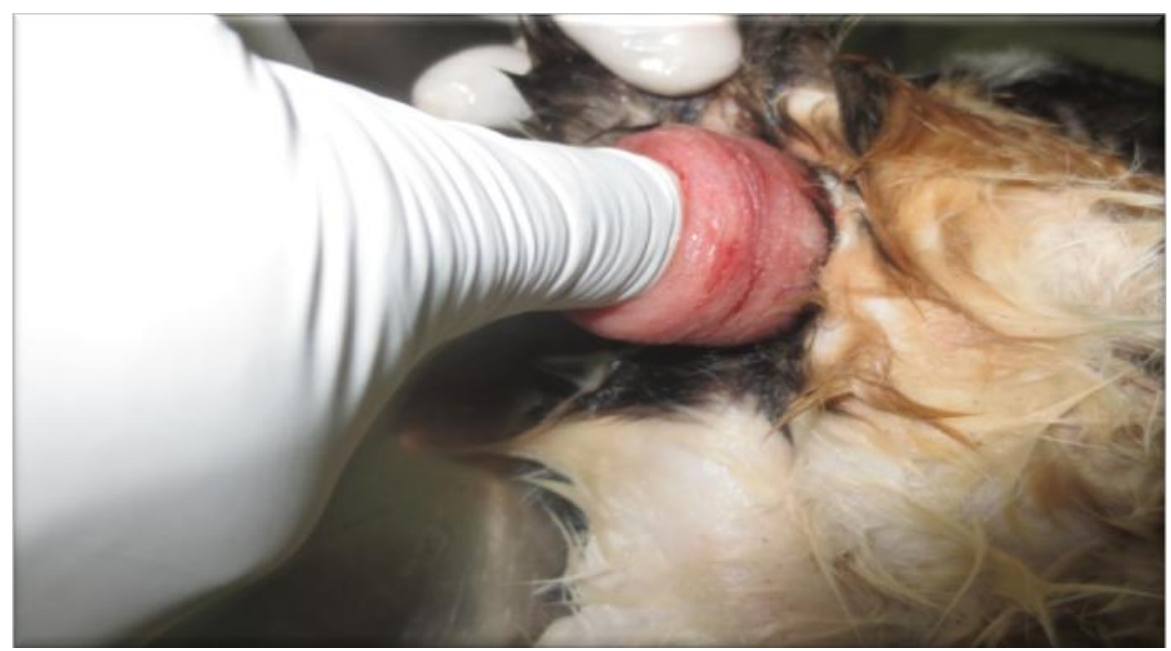


Fig.2 Manual reduction of uterine horn prolapse

In the present case prolapsed uterine mass was slightly oedematous and there was no any lacerations, necrosis or tear so, it is decided manual reduction and reposition of the mass followed by ovariohysterectomy since owner not interested to breed the cat in future. The cat was stabilised by administering $100 \mathrm{ml}$ of dextrose normal saline intravenously. The cat was pre-anaesthetised with injections xylazine @ $1 \mathrm{mg} / \mathrm{kg}$, atropine sulphate @ $0.04 \mathrm{mg} / \mathrm{kg}$ and ketamine @ $10 \mathrm{mg} / \mathrm{kg}$ i.m. General anaesthesia was induced with ketamine and diazepam at $10 \mathrm{mg} / \mathrm{kg}$ and $0.05 \mathrm{mg} / \mathrm{kg}$ i.v., respectively.

The anaesthesia was maintained with $1 / 3-1 / 2$ dose of the induction combination. Under general anaesthesia prolapsed mass was reduced and repositioned without any resistance by insertion of index finger through everted mass with mild pressure after lubrication of prolapsed mass with liquid paraffin. After preparation of the surgical site ovariohysterectomy was performed through mid-ventral approach and the abdominal incision was closed as per the standard procedure.

Post-operative care with antibiotics, intravenous fluids and supportive therapy was continued for 7 days. Post-operative dressing of the suture site was done on 3rd and 5th day. On day 7 the skin incision was completely opposed without any complication and the cat recovered uneventfully.

Uterine prolapse in cat is considered as a rare finding (Biddle and Macintire, 2000). It has been reported in queens ranging from 10 months to 6 years. Possible causes for uterine prolapse in cats may include rough handling during parturition, severe tenesmus, excessive relaxation and stretching of the pelvic musculature, intense dilation of the cervix, uterine atony due to metritis, incomplete separation of the placental membranes, rupture of the mesovarium and mesometrium (Bigliardi et al., 2014).

In the present case uterine prolapse might have occurred due to the continuous straining, excessive relaxation and stretching of pelvic musculature following the delivery of kittens. Diagnosis is made based on the history and visual inspection of the prolapsed uterine mass. Various treatment methods have been described including amputation of the everted uterus, manual reduction of the prolapsed mass and then perform ovario-hysterectomy (Vaughan and McGuckin, 1993).

In the present case prolapsed tissue mass successfully reduced and repositioned as described by Sathiamoorthy et al., (2011). Uterine horn prolapse may leads to adverse complications such as rupture of mesoovarium ligament it can be managed by laparotomy followed by ovariohysterectomy as described by Gokulakrishnan et al., (2009). Feline uterine prolapse can be successfully treated by manual reduction and repositioning followed by ovariohysterectomy.

\section{References}

Biddle, D.W. and Macintire, D.K. 2000. Obstetrical emergencies. Clinical Techniques in Small Animal Practice 15: 88-93.

Bigliardi, E., Ianni, F., Parmigiani, E., Cantoni, A.M. and Bresciani, C. 2014. Complete uterine prolapse without uterine mucosal eversion in a queen. J. of Small Anim. Pract., 55: 235-237.

Deroy, C., Bismuth, C., Carozzo, C. 2015. Management of a complete uterine prolapse in a cat. Journal of Feline Medicine and Surgery. Open Reports, 1-4. 
Gokulakrishnan, M., Vijayanand, V., Jayaprakash, R., Thilagar, S and Rajasundaram, R.C. 2009. Surgical management of bilateral uterine horn prolapsed in a queen cat. Indian J. Vet. Sur. 30(1): 66.

Johnston, S.D., Root Kustriz, M.V. and Oslon, P.N. 2001. Disorders of the feline uterus and uterine tubes (oviducts). Canine and Feline Theriogenology. WB Saunders, Philadelphia P.A. pp 463-471.

Jutkowitz, L.A. 2005. Reproductive emergencies. Veterinary Clinics of North America: Small Animal Practice
35: 397-420.

Roberts, D. and Straw Rodney, C. 1988. Uterine prolapse in a cat. Compendium Small Animal 10: 1294-1296.

Sathiamoorthy, T., Raja, S., Thirumuraugan, K and Kulasekar, K. 2011. Unilateral uterine horn prolapse with retained fetus in a queen cat. Indian Vet. J., 88(9): 120-121

Vaughan, L. and McGuckin, S. 1993. Uterine prolapse in a cat. Vet Rec. 132: 568.

Wallace, L.J., Henry, J.D. and Clifford, J.H. 1970. Manual reduction of uterine prolapse in a domestic Cat. Vet. Med. Small Anim. Clin. 65(6): 595-596.

\section{How to cite this article:}

Sabarinathan, A., N. Arunmozhi, U. S. Kalyaan, S. Rangasamy, T. Sathiamoorthy and Kulasekar, K. 2020. Management of Bilateral Uterine Horn Prolapse in a Queen Cat. Int.J.Curr.Microbiol.App.Sci. 9(05): 2754-2757. doi: https://doi.org/10.20546/ijcmas.2020.905.316 